\title{
Bio-inspired optimization algorithms applied to rectenna design
}

\author{
Menglong $\mathrm{He}^{*}$, Zhao Wang, Mark Leach, Zhenzhen Jiang and Eng Gee Lim
}

\author{
*Correspondence: \\ Enggee.lim@xjtlu.edu.cn \\ Department of Electric engineering, \\ Xi'an Jiaotong-Liverpool University, \\ Ren'ai road 111, Suzhou, People's \\ Republic of China
}

\begin{abstract}
A comparative study of the use of bio-inspired optimization technologies including the Cuckoo Search (CS) algorithm, the Differential Evolution (DE) algorithm, and Quantum-behaved Particle Swarm Optimization (QPSO) in the design of microstrip patch antennas for use in RF energy harvesting systems is presented. Radio frequency (RF) energy harvesting is considered as an eco-friendly energy source and has become a focus of intense research especially for use in distributed sensor networks. In a RF energy harvesting system, the antenna is responsible for capturing RF signals over a certain frequency band, and it is a vital element in determining the performance of the RF energy harvester. In this paper, a new mathematical weighted evaluation model involving antenna efficiency, center frequency, and bandwidth is proposed to evaluate the performance of a rectangular microstrip patch antenna (RMPA) for a RF harvesting system based on both the transmission-line model and the cavity model. With the evaluation model as the objective function, bio-inspired optimization approaches are utilized to determine the geometrical parameters of the optimal antenna based on given constraints. Moreover, the optimised designs of an antenna for harvesting energy from the Global System for Mobile Communications (GSM) frequency band are proposed via the mathematical model and bio-inspired optimization approaches using simulations. Furthermore, a comparative study of the DE, CS, and QPSO techniques is conducted via the evaluation of the properties of the antenna designs.
\end{abstract}

Keywords: RF harvesting system, Microstrip antenna, Cuckoo Search (CS) algorithm, Differential Evolution (DE) algorithm, Quantum-behaved particle swarm optimization (QPSO)

\section{Background}

With the advance of technologies including the Internet of Things (IoT) and wearable electronics, the demand for mobile electrical devices has surged. Battery depletion has become a fundamental bottleneck which limits the performance of these devices [1]. Considering the conventional fact that batteries have to be replaced or replenished manually after depletion, deeper implications exist for devices such as implantable heart pumps for which the replacement or recharging of the battery by cable is inconvenient and highcost [2]. RF energy harvesting technology provides an alternative to this and has recently received significant attention in the research community demonstrating its potential as a sustainable energy source for low power electronics [3-7].

The general anatomy of an RF energy harvester has been explained and examined. Some state of the art designs for receiving antenna including both narrow-band and

(c) The Author(s). 2018 Open Access This article is distributed under the terms of the Creative Commons Attribution 4.0 International License (http://creativecommons.org/licenses/by/4.0/), which permits unrestricted use, distribution, and reproduction in any medium, provided you give appropriate credit to the original author(s) and the source, provide a link to the Creative Commons license, and indicate if changes were made. The Creative Commons Public Domain Dedication waiver (http:// creativecommons.org/publicdomain/zero/1.0/) applies to the data made available in this article, unless otherwise stated. 
broad band antennas have been introduced. A mathematical weighted evaluation model involving antenna efficiency, center frequency, bandwidth, and gain was proposed to evaluate the performance of a RMPA for a RF harvesting system.The heuristic optimization approaches CS, DE, and QPSO were introduced and then utilized to give optimal designs for a GSM1800 receiving antenna. The proposed optimization algorithms successfully achieved optimal solutions under two different antenna size constraints. The overall comparison between QPSO, DE, and CS showed that the DE based optimization design approach provides the best solution and hence has the best globally optimum value search ability. This can significantly enhance antenna performance. Moreover, among the three optimization approaches, the CS algorithm has the best robustness. Furthermore, the simulations using QPSO based algorithm indicate its superiority displaying a faster convergence speed than DE and CS in the application of solving a complex electromagnetic problem. The advance of wireless communication has been boosting the power density of ambient RF energy. Among various sources of available ambient RF energy, the GSM frequency bands, including GSM1800 and GSM900, the Industrial, Scientific and Medical (ISM) band and the 3G band are the most promising to be explored. The average power densities of the conventionally utilized frequency bands measured in 2012 at all underground stations in London are summarized in Table 1 [8].

In brief, the RF energy harvester has the capability to convert RF signals (AC signal in nature) from ambient RF energy sources into a DC source. A typical centralized architecture of a RF energy harvesting system is shown in Fig. 1, it has two main components: a power management component and a rectenna. The rectenna consists of a receiving antenna, a matching circuit and a rectifier $[4,6]$. The power management module has two approaches for controlling the incoming energy flow: harvest-use and harvest-storeuse. The receiving antenna is responsible for capturing RF signals in the design frequency band, and it is a vital element in determining the performance of the energy harvesting system. Microstrip antennas have been greatly utilised in many communication technologies due to their low profile structure and low manufacturing cost [9]. In this study, the rectangular microstrip patch antenna (RMPA) is chosen for the rectenna design. The design will be optimized using 3 bio-inspired optimisation techniques The optimisation of a microstrip antenna for a RF energy harvester can be interpreted as a multi-objects nonlinear optimization problem. The solutions for an optimal patch antenna design can be attained by heuristic optimization algorithms.

Recently, considerable research has been directed towards the enhancement of antenna performance in RF harvesting systems. A variety of types of antenna design have been investigated including: fractal antennas, microstrip antennas and monopole antennas

Table 1 Average RF power density in London [8]

\begin{tabular}{lll}
\hline Band name & Frequency band & Average power density \\
\hline GSM1800 (BTx) & $1805 \mathrm{MHz} \sim 1880 \mathrm{MHz}$ & $84 \mathrm{nW} / \mathrm{cm}^{2}$ \\
GSM1800 (MTx) & $1710 \mathrm{MHz} \sim 1785 \mathrm{MHz}$ & $0.5 \mathrm{nW} / \mathrm{cm}^{2}$ \\
GSM900(BTx) & $925 \mathrm{MHz} \sim 960 \mathrm{MHz}$ & $36 \mathrm{nW} / \mathrm{cm}^{2}$ \\
GSM900(MTx) & $880 \mathrm{MHz} \sim 915 \mathrm{MHz}$ & $0.45 \mathrm{nW} / \mathrm{cm}^{2}$ \\
$3 G(B T x)$ & $2110 \mathrm{MHz} \sim 2170 \mathrm{MHz}$ & $12 \mathrm{nW} / \mathrm{cm}^{2}$ \\
$3 G(\mathrm{MTX})$ & $1920 \mathrm{MHz} \sim 1980 \mathrm{MHz}$ & $0.46 \mathrm{nW} / \mathrm{cm}^{2}$ \\
WiFi & $2400 \mathrm{MHz} \sim 2500 \mathrm{MHz}$ & $6 \mathrm{nW} / \mathrm{cm}^{2}$ \\
\hline
\end{tabular}




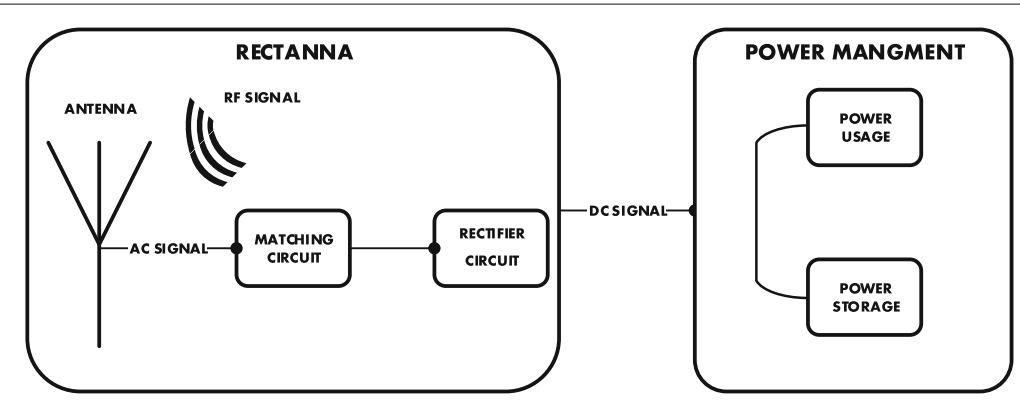

Fig. 1 Architecture of RF harvesting system. This figure shows a typical centralized architecture of a RF energy harvesting system, including two main components: a power management component and a rectenna

[10-12]. Table 2 shows the antenna performance of some state of art designs. As shown in Table 2, research efforts have been made for broad-band antenna(typical on order of $1 \mathrm{GHz})$ as in [13-17, 42], and for narrow-band antenna in [10, 39-41, 43]. The dipole antenna is the focus of the work in [13, 16], and the monopole in [11, 41]. Authors in $[17,39,40,43]$ have demonstrated the excellent performance of the microstrip antenna. Nevertheless, most of the designs that have been mentioned previously do not consider the minimization of antenna size, which could potentially limit the application of the RF harvester. In [18-23], heuristic optimization approaches including the DE and CS algorithms have been utilized to determine the geometrical characteristics of the optimal patch antenna. Conventionally, patch antennas suffer from a narrow bandwidth. Accordingly, PSO and curve fitting have been introduced in [18], and the overall bandwidth of the inverted E-shaped microstrip patch antenna was increased by $15 \%$. Authors in [20-23] have proposed mathematical models of the RMPA considering the center frequency as well as return loss, and the optimal designs are obtained via the CS, PSO, and $\mathrm{DE}$ algorithms. However, none of them involve improving antenna gain, widening antenna bandwidth, and minimization of antenna size.

\section{Method}

In a RF energy harvesting system, the antenna, which is responsible for receiving RF signals over a certain frequency band, is an important element in the design of the RF energy harvester. The design of the antenna involves several parameters, some of which induce

Table 2 Summary of performance of variety of up-to-date antenna design

\begin{tabular}{lllll}
\hline Literature & Antenna type & Designed band & Antenna gain & Return loss \\
\hline M. Arrawatia, et al. [39] & Differential Microstrip & $0.87 \mathrm{GHz} \sim 1.05 \mathrm{GHz}$ & $8.5 \mathrm{dBi}$ & $17.2984 \mathrm{~dB}$ \\
S. Ghosh, et al. [40] & Microstrip & $0.935 \mathrm{GHz} \sim 0.96 \mathrm{GHz}$ & $4.0947 \mathrm{~dB}$ & $12.82 \mathrm{~dB}$ \\
H. Saghlatoon, et al. [41] & Planar Monopole & $0.6 \mathrm{GHz} \sim 1.5 \mathrm{GHz}$ & $3.432 \mathrm{dBi}$ & $27.5 \mathrm{~dB}$ \\
A. Dadgarpour, et al. [42] & Bow-tie & $2.5 \mathrm{GHz} \sim 3.9 \mathrm{GHz}$ & $\geq 10.9 \mathrm{dBi}$ & $27.68 \mathrm{~dB}$ \\
M. W. Zeng, et al. [10] & Fractal Loop & $1.73 \mathrm{GHz} \sim 1.84 \mathrm{GHz}$ & $3.2 \mathrm{dBi}$ & $31.25 \mathrm{~dB}$ \\
M. Arrawatia, et al.[11] & Triangular Monopole & $0.85 \mathrm{GHz} \sim 1.94 \mathrm{GHz}$ & $\geq 2 \mathrm{dBi}$ & 19.085 \\
J. Wen, et al.[13] & Dipole & $1.7 \mathrm{GHz} \sim 3.6 \mathrm{GHz}$ & $9.05 \mathrm{dBi}$ & $33.75 \mathrm{~dB}$ \\
D. Yang, et al.[14] & Planar Quasi-Yagi & $3.15 \mathrm{GHz} \sim 10.65 \mathrm{GHz}$ & $7.6 \mathrm{dBi}$ & $24.714 \mathrm{~dB}$ \\
R. Maher, et al. [15] & Planar & $2.1 \mathrm{GHz} \sim 7 \mathrm{GHz}$ & $11.4585 \mathrm{dBi}$ & 44.1499 \\
J.Y. Li, et al. [16] & Dipole & $2.48 \mathrm{GHz} \sim 9.51 \mathrm{GHz}$ & $\geq 6 \mathrm{dBi}$ & 19.08 \\
K. P. Esselle, et al. [17] & Microstrip & $4 \mathrm{GHz} \sim 9.5 \mathrm{GHz}$ & $\geq 7.4 \mathrm{dBi}$ & 35 \\
W. Han, et al. [43] & Circular Microstrip & $6.12 \mathrm{GHz} \sim 6.84 \mathrm{GHz}$ & $8.7 \mathrm{dBi}$ & $14 \mathrm{~dB}$ \\
\hline
\end{tabular}


contradictory modifications of antenna performances. In this paper, a new mathematical weighted evaluation model involving antenna efficiency, center frequency, and bandwidth is proposed to evaluate the performance of a rectangular microstrip patch antenna (RMPA) based on both the transmission-line model and the cavity model. With the mathematic modeling of a RMPA, three bio-inspired optimization technologies including the Cuckoo Search (CS) algorithm, the Differential Evolution (DE) algorithm, and Quantum-behaved Particle Swarm Optimization (QPSO)are used to optimize the design of RMPA with certain constraints. The simulation processes and designed antennas' performances are also presented and compared. With the evaluation model as the objective function, bio-inspired optimization approaches are utilized to determine the geometrical parameters of the optimal antenna based on given constraints.

The paper is organized as follows:"Mathematic modeling of RMPA"section introduces the basic architecture and properties of a RMPA, and a mathematical model is proposed based on the cavity and transmission line models. Additionally, the objective function and constraints for optimization are derived. The "Bio-inspired algorithms for antenna design" section describes the current implementation of the optimal antenna design algorithms including QPSO, CS, and DE. Finally, based on the performance of designed antennas, the properties of three bio-inspired algorithms are discussed and compared.

\section{Mathematic modeling of RMPA}

The efficiency of a RF energy harvester is defined as the ratio of output power $\left(P_{\text {out }}\right)$ over input power $\left(P_{i n}\right)$. Conventionally, the harvested RF power from the rectenna is expressed as follows:

$$
P_{\text {out }}=\eta_{a} \cdot \eta_{m} \cdot \eta_{r} \cdot P_{\text {in }}
$$

where the $\eta_{a}, \eta_{m}$ and $\eta_{r}$ respectively represent the efficiency of receiving antenna, impedance matching network, and rectifying circuit. The magnitude of $P_{T}$ is correlated with the design frequency band of antenna. Accordingly, the optimum antenna design for a RF harvesting system requires two features: high antenna efficiency and appropriate frequency band. In more detail, the performance of the antenna used for a RF energy harvester mainly depends on the antenna gain, bandwidth, return loss, and center frequency. However, there is a trade-off between antenna size and performance.

\section{Architecture of a RMPA}

The typical architecture of a rectangular microstrip patch antenna (RMPA) with inset feed contains four geometric parameters ( $\left.\mathrm{L}, \mathrm{W}, \mathrm{g}, L_{d}\right)$ as shown in Fig. 2, and it consists of three layers including patch, substrate, and ground plane. Normally the patch and microstrip feed line are fabricated on the upper surface of the dielectric substrate, and a metal ground plane is placed on the bottom. The four most popular feeding configurations are: the microstrip line, coaxial probe, aperture coupling, and proximity coupling, among which the inset microstrip feed line has the simplest configuration to implement and control [9] By far, the rectangular patch is the most widely used microstrip antenna, and can be modeled and analyzed by both transmission line model and cavity theory. The mathematical formulations of the RMPA have been demonstrated and derived in the following section, where the notations used in the model are as shown in Tables 3 and 4. 


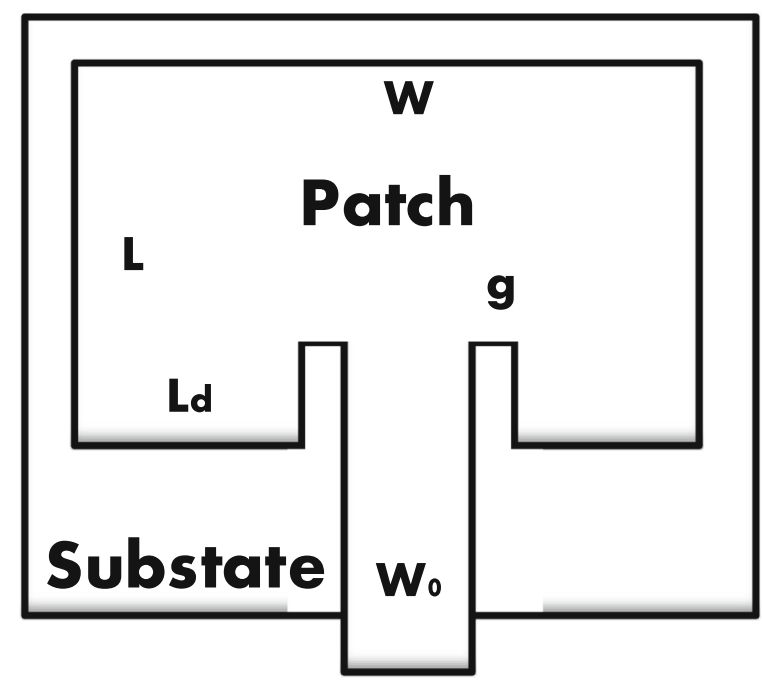

Fig. 2 Architecture of a RMPA. This figure shows the typical architecture of a three-layer rectangular microstrip patch antenna (RMPA) with inset feed contains four geometric parameters ( $L, W, g, L d)$

\section{Problem formulation}

The objective function is to minimize the deviation between the designed antenna and the optimum antenna.

$$
\left\{\begin{array}{l}
\Phi\left(W, L, y_{0}, g, W_{0}\right)=\left[\delta B, \delta A_{e}, \delta G\right] \cdot W^{\mathbf{T}} \\
\text { Obj.Fun }=\min \Phi\left(W, L, y_{0}, g\right)
\end{array}\right.
$$

Table 3 Nomenclature of important parameters

\begin{tabular}{llll}
\hline $\boldsymbol{F}$ & Center frequency of antenna & $A_{e}$ & Antenna efficiency of antenna \\
$\boldsymbol{B}$ & Band width of antenna & $R_{L}$ & Return loss of antenna \\
$P_{i n}$ & Input power of rectenna & $P_{\text {out }}$ & Output power of rectenna \\
$\eta_{a}$ & Efficiency of antenna & $\eta_{m}$ & Efficiency of matching circuit \\
$\eta_{r}$ & Efficiency of rectifier circuit & $P_{T}$ & Transmitted power from source \\
$W$ & Width of RMPA & $L$ & Length of RMPA \\
$W_{0}$ & Feed width of RMPA & $L_{d}$ & Inset feed length \\
$g$ & Notch width & $\varepsilon_{0}$ & Vacuum dielectric constant \\
$X_{\text {min }}$ & Minimum constraint of antenna size & $X_{\text {max }}$ & Maximum constraint of antenna size \\
$\mu_{0}$ & Vacuum permeability & $Z_{i n}$ & Antenna input impedance \\
$\Gamma$ & Voltage reflection coefficient & $V_{S W R}$ & Voltage standing wave ratio \\
$Q_{r a d}$ & Quality factor due to radiation losses & $Q_{C}$ & Quality factor due to conduction losses \\
$Q_{d}$ & Quality factor due to dielectric losses & $Q_{S W}$ & Quality factor due to surface waves \\
$Q_{t}$ & Total quality factor & tan $\delta$ & Loss tangent of the substrate material \\
$G$ & Antenna gain & $V_{0}$ & The speed of EM wave \\
$k_{0}$ & Spatial angular frequency of wave & $G_{a b s}$ & Absolute gain \\
$P_{r a d}$ & Radiation power of antenna & $U_{m a x}$ & Maximum radiation intensity \\
$D_{0}$ & Directivity of antenna with single slot & $D_{A F}$ & Directivity of array factor AF \\
$e_{B W}$ & Efficient bandwidth ratio & $F_{A L}$ & Aimed lower conner frequency \\
$F_{A H}$ & Aimed upper conner frequency & $F_{D L}$ & Designed lower conner frequency \\
$F_{D H}$ & Designed upper conner frequency & $\sigma$ & Conductivity of patch \\
$D$ & Directivity of antenna & $e_{C d}$ & ntenna Radiation efficiency \\
\hline & & & \\
\hline
\end{tabular}


Table 4 Nomenclature of important parameters

\begin{tabular}{ll}
\hline$\hbar$ & Planck's constant \\
\hline$V(r)$ & Potential energy distribution \\
Mbest & Best position of particle in the direction d \\
$\beta$ & Contraction-expansion coefficient \\
$p_{j . d}$ & Local attractor of particle $\mathrm{j}$ in direction d \\
$u$ & Gaussian distributed number within $[0,1]$ \\
$k$ & Random value within $[0,1]$ \\
\hline
\end{tabular}

where $\mathrm{W}=\left[\begin{array}{lll}w_{1} & w_{2} & w_{3}\end{array}\right]$ is a weight matrix. Moreover, $\delta F, \delta B, \delta A_{e}$, and $\delta R_{L}$ shows the deviation between the performance of designed antenna and the performance of the optimal antenna. The inequality geometry constraints are five groups of inequations which can be obtained from the architecture of RMPA

$$
\left\{\begin{array}{l}
g<\frac{L}{2} \\
y_{0}<L \\
X_{\min }<L<X_{\max } \\
X_{\min }<W<X_{\max }
\end{array}\right.
$$

Moreover, the geometrical requirement for applying the transmission line model of the RMPA is [9].

$$
W \gg h .
$$

\section{Input impedance of a RMPA}

The input impedance of the RMPA $Z_{\text {in }}$ can be obtained from the equivalent transmission line circuit as shown in Fig. 3. The admittance of the antenna with two slots $\left(Y_{1}\right.$ and $\left.Y_{2}\right)$ is given by [24-26]:

$$
\begin{aligned}
& Y_{1}=G_{1}+j B_{1} \\
& Y_{2}=G_{2}+j B_{2}
\end{aligned}
$$

where $G_{1}=G_{2}, B_{1}=B_{2}$ and owing to that the two slots of the antenna are identical.

With the field expression derived according to the cavity model $[9,25]$, the conductance of a single slot is defied as follows:

$$
G_{1}=\frac{2 P_{\text {rad }}}{\left|V_{0}\right|^{2}}
$$

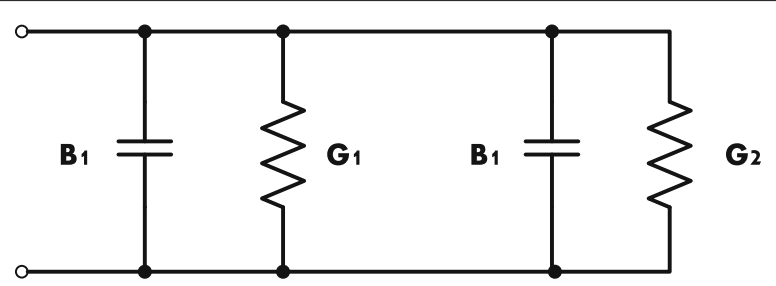

Fig. 3 Equivalent transmission line model circuit. This figure shows the equivalent transmission line model circuit of a RMPA, including capacitances and resistances 
where $P_{\text {rad }}$ is defined as the radiated power which can be calculated by [25, 26]:

$$
P_{\text {rad }}=\frac{\left|V_{0}\right|^{2}}{2 \pi \eta_{0}} \int_{0}^{\pi}\left[\frac{\sin \left(\frac{k_{0} W}{2} \cos \vartheta\right)}{\cos (\vartheta)}\right]^{2} \sin ^{3} \vartheta \delta \vartheta .
$$

Accordingly, the conductance of the antenna is defined as:

$$
G_{1}=G_{2}=\frac{1}{120 \pi^{2}} \int_{0}^{\pi}\left[\frac{\sin \left(\frac{k_{0} W}{2} \cdot \cos \vartheta\right)}{\cos (\vartheta)}\right]^{2} \sin ^{3} \vartheta \delta \vartheta .
$$

Considering the mutual effect between the two slots, the total resonant input admittance of the RMPA with no inset feed can be obtained as [9, 24]:

$$
\left\{\begin{array}{l}
\dot{Y_{2}}=G_{1}-j B_{1} \\
Y=Y_{1}+\dot{Y}_{2}=2\left(G_{1}+G_{12}\right)
\end{array}\right.
$$

where the mutual conductance $G_{12}$ is $[9,24,26]$.

$$
G_{12}=\frac{1}{120 \pi^{2}} \int_{0}^{\pi}\left[\frac{\sin \left(\frac{k_{0} W}{2} \cos \vartheta\right)}{\cos (\vartheta)}\right]^{2} J_{0}\left(k_{0} L \sin \vartheta\right) \sin ^{3}(\vartheta) \delta \vartheta
$$

where $J_{0}$ is the Bessel function of the first kind of order zero, and accordingly the input resistance for the inset feed case can be approximately expressed as [26]:

$$
Z_{\text {in }}=\frac{1}{2\left(G_{1}+G_{12}\right)} \cos ^{2}\left(\frac{\pi}{L} L_{d}\right) .
$$

\section{Resonant frequency of A RMPA}

Owing to the fact that the dimensions of patch are not infinite along the length and width, the fields at the edges of patch is nonhomogeneous. Figure 4 shows typical electric field lines caused by the fringing effect, which makes the electric size of the patch larger than the physical dimensions. Thus, the effective dielectric constant $\epsilon_{\text {eff }}$ and effective patch width $L_{\text {eff }}$ are introduced to take account of the fringing effect. Accordingly, the resonant frequency of the dominant mode of the RMPA is derived as [9, 24, 25].

$$
F\left(W, L, y_{0}, g\right)=\frac{1}{2 L_{\text {eff }} \sqrt{\varepsilon_{\text {reff }}} \sqrt{\mu_{0} \varepsilon_{0}}}
$$

The effective dielectric constant $\epsilon_{\text {eff }}$ and effective patch length $L_{\text {eff }}$ can be calculated by:

$$
\left\{\begin{array}{l}
\varepsilon_{e f f}=\frac{\varepsilon_{r}+1}{2}+\frac{\varepsilon_{r}-1}{2}\left[1+12 \frac{h}{W}\right]^{-1 / 2} \\
L_{e f f}=L+2 \Delta L
\end{array}\right.
$$

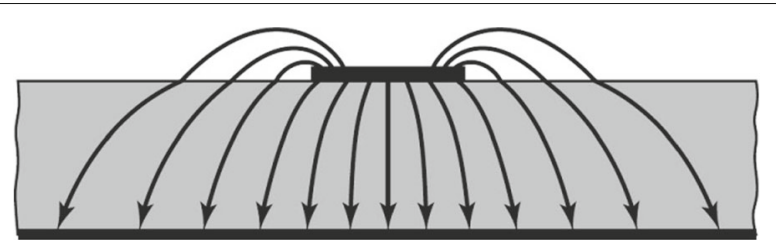

Fig. 4 Electric field caused by fringing effect. This figure shows the typical electric field lines of a RMPA 
where $\Delta L$ is the normalized extension of the length and given as:

$$
\Delta L=0.412 h \frac{\left(\varepsilon_{\text {reff }}+0.3\right)\left[\frac{W}{h}+0.264\right]}{\left(\varepsilon_{\text {reff }}-0.258\right)\left[\frac{W}{h}+0.8\right]} .
$$

The notch width can be calculated based on the designed center frequency, and the empirical equation for which is proposed as [27]:

$$
g=\frac{v_{0}}{\sqrt{2 \epsilon_{e f f}}} \frac{4.65 \cdot 10^{-12}}{f}
$$

\section{Antenna gain of a RMPA}

Antenna gain is defined as the ratio of radiation intensity in a given direction to the intensity that would be obtained when the power accepted is isotropically distributed [9]. The relative gain is the ratio of power gain to the gain of a reference antenna [9]. Antenna gain is mathematically deified as $[9,24]$ :

$$
G\left(W, L, y_{0}, g\right)=4 \pi \frac{U(\theta, \phi)}{P_{\text {in }}}
$$

Antenna gain can also be expressed as a function of antenna directivity as:

$$
G(\theta, \phi)=e_{c d}[4 \pi U(\theta, \phi)]=e_{c d} D_{t}
$$

Hence, antenna gain depends on radiation efficiency as well as directivity. The two parameters are calculated separately as follows.

The quality factor of the antenna, or the figure-of-merit, is representative of antenna loss, and it in general can be written as $[9,26]$ :

$$
\frac{1}{Q_{t}}=\frac{1}{Q_{\text {rad }}}+\frac{1}{Q_{c}}+\frac{1}{Q_{d}}+\frac{1}{Q_{s w}}
$$

where the quality factors of various losses can be expressed as :

$$
\left\{\begin{array}{l}
Q_{c}=h \sqrt{\pi f \mu \sigma} \\
Q_{d}=\frac{1}{\tan (\delta)} \\
Q_{\text {rad }}=\frac{2 \omega \epsilon_{r} K}{h G_{t} / l}
\end{array}\right.
$$

As for the RMPA aperture operating in the dominant $T M_{010}^{x}$ mode, the $G_{t} / l$ and $K$ can be calculated by [9].

$$
\left\{\begin{array}{l}
K=\frac{\iint_{\text {area }}|E|^{2} d A}{\oint_{\text {perimeter }}|E|^{2} d l}=\frac{L}{4} \\
G_{t} / l=\frac{G_{1}}{W}
\end{array}\right.
$$

In an ideal situation the loss caused by conduction $Q_{c}$ and the loss by surface wave $Q_{s w}$ can be ignored. Thus, the total loss can be approximately expressed as:

$$
Q_{t}=\frac{Q_{d} Q_{r a d}}{Q_{d}+Q_{\text {rad }}}
$$

and $e_{c d}$, the radiation efficiency of an antenna, can be derived through the quality factor as:

$$
e_{c d}=\frac{Q_{t}}{Q_{\text {rad }}}=\frac{Q_{d}}{Q_{d}+Q_{\text {rad }}}
$$


Furthermore, directivity, one of the most important antenna parameters, conventionally implies the ratio of maximum radiation intensity to the averaged value over all directions, and is expressed by:

$$
D_{t}=\frac{4 \pi U_{\max }}{P_{\text {rad }}}
$$

In the case of a RMPA with two radiating slots, the antenna directivity can be calculated by following equation $[24,25]$.

$$
D_{t}=D_{0} D_{A F}
$$

where the directivity for an antenna with one slot $D_{0}$ is defined as [24]:

$$
D_{0}=\left(\frac{4 \pi^{2} W^{2}}{\lambda_{0}^{2}}\right) /\left(\int_{0}^{\pi}\left[\frac{\sin \left(\frac{k_{0} W}{2} \cos \vartheta\right)}{\cos (\vartheta)}\right]^{2} J_{0}\left(k_{0} L \sin \vartheta\right) \sin ^{3}(\vartheta) \delta \vartheta\right) .
$$

Moreover, the directivity of the array factor AF $D_{A F}$ is calculated as follows [9]:

$$
D_{A F}=\frac{2}{1+G_{12} / G_{1}}
$$

Therefore, the antenna gain in $\mathrm{dBi}$ can be demonstrated by the following equation.

$D_{t}=\left(\frac{8 \pi^{2} W^{2}}{\lambda_{0}^{2}}\right) /\left(\left(\int_{0}^{\pi}\left[\frac{\sin \left(\frac{k_{0} W}{2} \cos \vartheta\right)}{\cos (\vartheta)}\right]^{2} J_{0}\left(k_{0} L \sin \vartheta\right) \sin ^{3}(\vartheta) \delta \vartheta\right) \cdot\left(1+G_{12} / G_{1}\right)\right.$

Thus, the antenna gain can be obtained via the directivity and radiation efficiency of RMPA as shown in Eq. 29.

$$
G\left(W, L, y_{0}, g\right)=\frac{Q_{d}}{Q_{d}+Q_{r a d}} D_{t}
$$

Deviation between the designed antenna gain and the optimal antenna gain (here we use $10 \mathrm{dBi}$ as the desired gain) is defined as follows.

$$
\delta G\left(W, L, y_{0}, g\right)=\left(10-\frac{Q_{d}}{Q_{d}+Q_{\text {rad }}} D_{t}\right) / 10
$$

\section{Antenna efficiency of a RMPA}

The overall antenna efficiency due to mismatch reflections and $I R^{2}$ losses is used to consider losses at the input terminals and within the antenna. Thus, the antenna efficiency can be written as:

$$
A_{e}=e_{r} e_{c d}=e_{c d}\left(1-|\Gamma|^{2}\right)
$$

In the transmission line model circuit, the return loss is determined by both the VSWR and $\Gamma$ which can be calculated using:

$$
\left\{\begin{array}{l}
\Gamma=\frac{Z_{\text {in }}-Z_{0}}{Z_{\text {in }}+Z_{0}} \\
V S W R=\frac{1+|\Gamma|}{1-|\Gamma|}
\end{array}\right.
$$

In telecommunications systems, return loss is defined as the power loss for the signal reflected by a discontinuity during transmission, and it is mathematically defined as:

$$
R_{L}\left(W, L, y_{0}, g\right)_{d B}=10 \log _{10} P_{i} / P_{0}
$$


Assuming the characteristic impedance of the feed line is equal to $50 \Omega$, the return loss can be expressed by Eq. (34), The input independence of the RMPA has also been calculated using Eq. (12).

$$
\left\{\begin{array}{l}
R_{L}\left(W, L, y_{0}, g\right)_{d B}=-20 \log _{10}(|\Gamma|)=-20 \log _{10} \frac{Z_{i n}-50}{Z_{i n}+50} \\
R_{L}\left(W, L, y_{0}, g\right)_{d B}=-20 \log _{10}\left(\frac{\cos ^{2}\left(\frac{\pi}{L} d\right)-100\left(G_{1}+G_{12}\right)}{\cos ^{2}\left(\frac{\pi}{L} d\right)+100\left(G_{1}+G_{12}\right)}\right)
\end{array}\right.
$$

Therefore, the overall antenna efficiency can be expressed as follows:

$$
A_{e}\left(W, L, y_{0}, g\right)=e_{r} e_{c d}=\frac{Q_{d}}{Q_{d}+Q_{r a d}}\left(1-\left(\frac{\cos ^{2}\left(\frac{\pi}{L} d\right)-100\left(G_{1}+G_{12}\right)}{\cos ^{2}\left(\frac{\pi}{L} d\right)+100\left(G_{1}+G_{12}\right)}\right)^{2}\right)
$$

Additionally, the derivation between designed antenna efficiency and the optimal antenna efficiency can be defined as:

$$
\delta A_{e}\left(W, L, y_{0}, g\right)=\left|\left(1-A_{e}\right)\right|
$$

\section{Bandwidth of a RMPA}

The magnitude of the bandwidth varies with VSWR. The bandwidth and percentage bandwidth of an antenna (VSWR $\leq 2$ ) can be calculated by:

$$
\left\{\begin{array}{l}
\% B W\left(W, L, y_{0}, g\right)=\frac{A h}{\lambda_{0} \sqrt{\epsilon_{r}}} \sqrt{\frac{W}{L}} \\
B W\left(W, L, y_{0}, g\right)=\frac{A h}{\lambda_{0} \sqrt{\epsilon_{r}}} \sqrt{\frac{W}{L}} \cdot F\left(W, L, W_{0}, y_{0}, g\right)
\end{array}\right.
$$

where A can take one of the three following values [28]

$$
A=\left\{\begin{array}{l}
180, \frac{A h}{\lambda_{0} \sqrt{\epsilon_{r}}} \leq 0.045 \\
200,0.045 \leq \frac{A h}{\lambda_{0} \sqrt{\epsilon_{r}}} \leq 0.075 \\
220,0.075 \leq \frac{A h}{\lambda_{0} \sqrt{\epsilon_{r}}}
\end{array}\right.
$$

Moreover, the percentage bandwidth can also be calculated using the quality factor and the corresponding VSWR, as [9].

$$
\frac{\delta f}{f_{0}}=\frac{V S W R-1}{Q_{t} \sqrt{V S W R}}
$$

To demonstrate the accuracy of the design frequency band, concept of efficient covered bandwidth ratio is proposed as below. Figure 5 shows the physical meaning of efficient covered bandwidth which describes the region of the desired frequency bandwidth

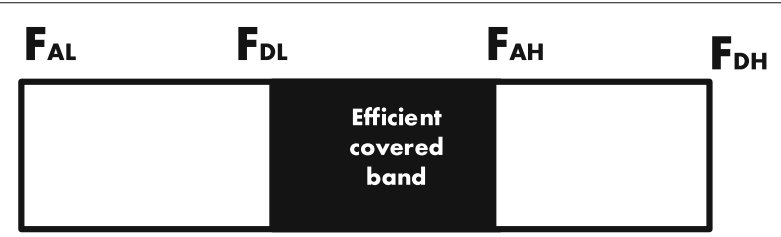

Fig. 5 Defined efficient bandwidth. This figure shows the physical meaning of efficient covered bandwidth which describes the region of the desired frequency bandwidth covered by the design bandwidth 
covered by the design bandwidth. Thus, the efficient covered bandwidth ratio $e_{B W}$ is proposed mathematically as:

$$
e_{B W}= \begin{cases}\frac{f_{D H}-f_{D L}}{f_{A H}-f_{A L}}, & F_{D H} \leq F_{A H}, F_{A L} \leq F_{D L} \\ \frac{f_{D H}-f_{A L}}{f_{A H}-f_{A L}}, & F_{D H}<F_{A H}, F_{D L}<F_{A L} \\ \frac{f_{A H}-f_{D L}}{f_{A H}-f_{A L}}, & F_{A H}<F_{D H}, F_{A L}<F_{D L} \\ 0, & F_{D H} \leq F_{A L} \quad \text { or } \quad F_{A H} \leq F_{D L}\end{cases}
$$

Thus, the derivation between design antenna bandwidth and the optimal antenna bandwidth (VSWR $\leq 2)$ is described by Eq. (41):

$$
\delta B_{e}\left(W, L, y_{0}, g\right)=e_{B W}
$$

\section{Bio-inspired algorithms for antenna design}

\section{CS algorithm for antenna design}

The Cuckoo Search (CS) algorithm is a stochastic global search algorithm, inspired by obligated brood parasitic behavior of some cuckoo species, and it was developed by XinShe Yang and Deb in 2009 [29, 30]. The cuckoo search imitates aggressive reproduction strategy of some species of cuckoo birds in nature. The process of CS follows three idealized rules [29]: 1) Each cuckoo lays one egg in a random nest which will be a potential solution. 2) The next generation of eggs will only be carried over by the best nests with the highest quality of eggs, which proposes only locally optimal solutions can survive in next generation. 3) The number of available host nests is fixed, and eggs laid by the cuckoo can be discovered by the host birds with a probability equal to $P_{a}$. The general system-equation of the CS is based on lévy flight as [29]:

$$
x^{t+1}=x^{t}+\alpha \oplus \operatorname{lévy}(\lambda)
$$

where $x^{t}$ is the current solution, and $x^{t+1}$ is the newly generated solution. Additionally, the lévy( $\lambda$ ) follows the lévy distribution [29].

$$
\text { lévy }(\lambda) \sim t^{-\lambda} \quad(1 \leq \lambda \leq 3) .
$$

The step size $\alpha$ follows the Mantegna Algorithm in which the step size can be obtained by $[29,30]$ :

$$
\alpha=\frac{u}{|v|^{1 / \beta}}
$$

where the $\mathrm{u}$ as well as $\mathrm{v}$ follow normal distribution [29].

$$
\left\{\begin{array}{l}
\sigma u=\frac{\Gamma(1+\beta) \sin \pi(\beta / 2)}{\Gamma(1+\beta) /(2 \beta) 2^{(\beta-1) / 2}} \\
\sigma v=1
\end{array}\right.
$$

When the $\beta$ is set to 1 , the above two formula reduce to Eq. (46).

$$
\left\{\begin{array}{l}
\sigma u=\frac{\Gamma 2}{\Gamma 1}=1 \\
\sigma v=1
\end{array}\right.
$$

Therefore, the overall procedure of optimizing the antenna design for a RF harvesting system is shown as Algorithm 1, which has been implemented by MATLAB and Python.

\section{Differential evolution for RMPA design}

Differential evolution (DE), one of the most powerful stochastic and population based optimization algorithms, is inspired by the Darwinian principles for the natural evolution 


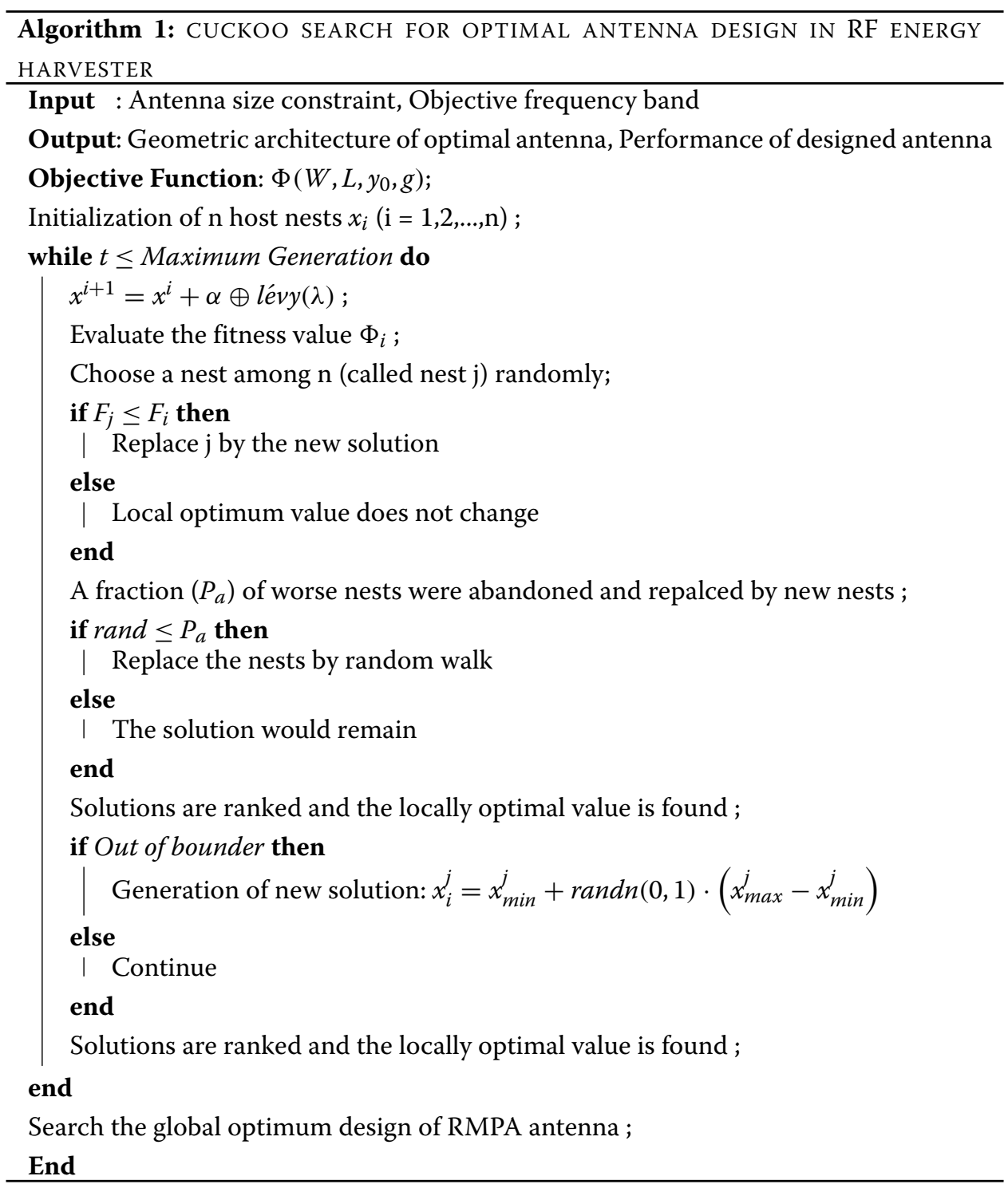

of species. DE was initially introduced by Storn and Price in 1996 [31-33]. As a variant of the Genetic Algorithm (GA), DE mainly has three advantages including easy implementation, high performance and few control parameters $[32,33]$. The overall procedure for DE has four steps: initialization, mutation, crossover and selection. Firstly, the initial value of the $j$ th parameter in the $i$ th individual at generation zero is given by [33].

$$
x_{i}^{j}=x_{\text {min }}^{j}+\operatorname{randn}(0,1) \cdot\left(x_{\text {max }}^{j}-x_{\text {min }}^{j}\right)
$$

where the randn $(0,1)$ is a uniformly distributed random variable. The mutation operation will be employed to generate a new potential solution, of which there are five frequently used mutation strategies [33]. The equation for the DE/rand/1 strategy is given by [33].

$$
V_{i, G}=X_{r_{1}, G}+F \cdot\left(X_{r_{3}, G}-X_{r_{2}, G}\right)
$$

where $V_{i, G}$ are the mutant solutions generated by the current solutions including $X_{r_{1}^{i}, G}$, $X_{r_{2}, G}$, and $X_{r_{3}, G}$. Here $\mathrm{F}$ is a positive control factor. After the mutation, the crossover 
operation is applied to generate more potential new solutions based on $V_{i, G}$ and $X_{i, G}[32]$ :

$$
U_{i, G}^{j}=\left\{\begin{array}{l}
V_{i, G}^{j} \text { ifrand }_{j}[0,1] \leq C R \\
X_{i, G}^{j} \text { ifrand } j[0,1]>C R
\end{array}\right.
$$

Finally, the locally optimal solutions will be selected and the global optimum value can be found. Based on the four steps mentioned, the overall pseudo code also implemented in MATLAB and Python is shown as Algorithm 2.

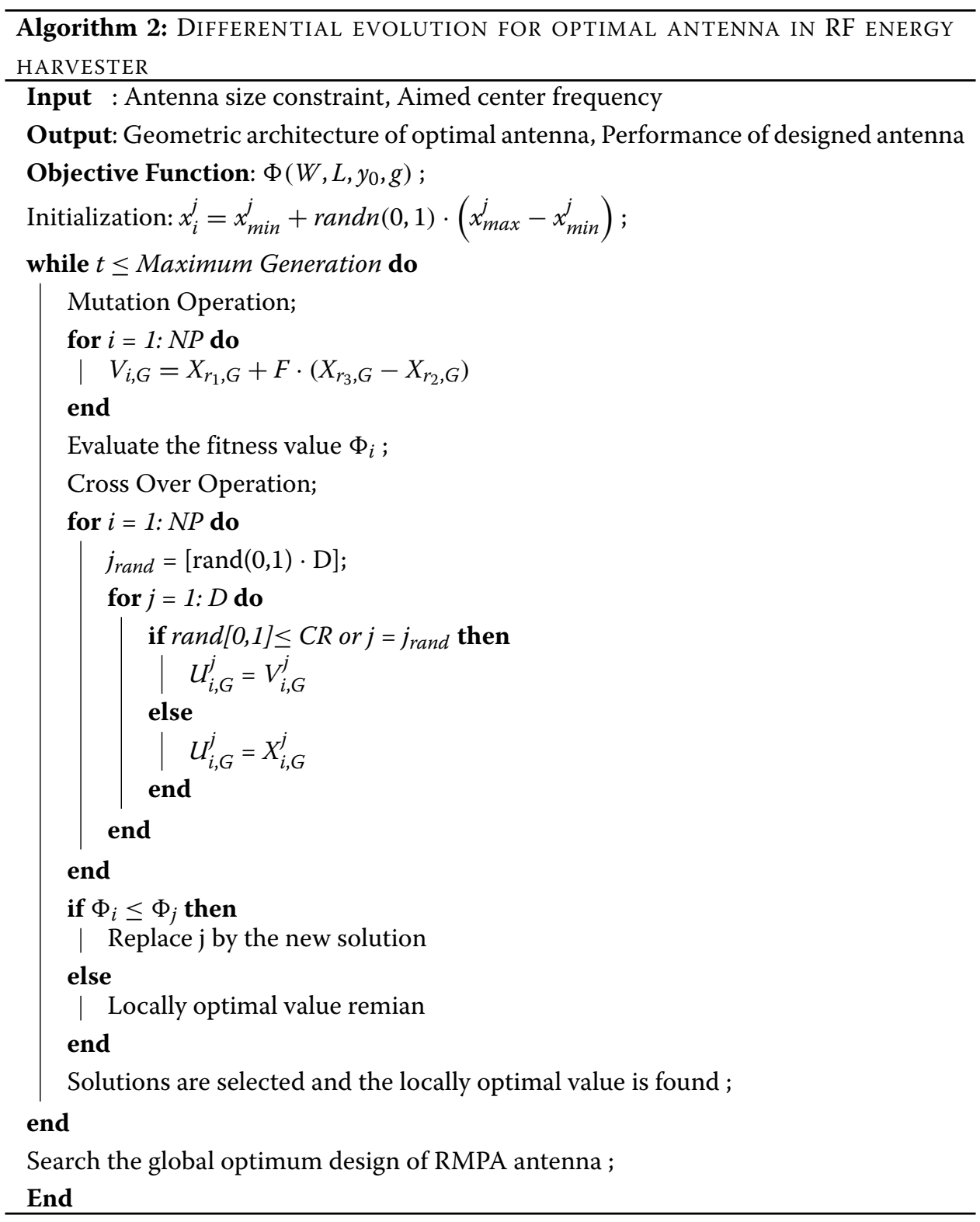

\section{QPSO algorithm for RMPA design}

The evolutionary particle swarm optimization (PSO) is a global search technique with incomparable advantages in searching speed and precision. It was originally introduced 
by Kennedy and Eberhar [34-36]. The basic idea of PSO is inspired by the social behavior of interactions between members including birds and fish. There are three main attractive features of PSO: robust search ability, fast computation and easy implementation $[34,35,37]$. In addition to its advantages, it has a slow solution fine-tuning ability of the solution, which sucks the solution towards the locally optimum value.

Accordingly, QPSO, as the modified PSO technology, was proposed to enhance the global search ability. The essential difference between the QPSO and PSO is that the movement of particles follows the principles of quantum mechanics instead of Newtonian mechanics.

The general governing equation in quantum mechanics of QPSO is the time independent Schrödinger equation:

$$
\widehat{H}(r)=-\frac{\hbar^{2}}{2 m} \nabla^{2}+V(r)
$$

With the Monte Carlo method [34, 38], the position of particles can be updated by:

$$
\left.x_{d}^{j}(k+1)=p_{j . d}+\beta \cdot \mid \text { Mbest } t_{d}^{j}-x_{d}^{j}(k)\right) \mid \ln (1 / u)
$$

where the Mbest $_{d}^{j}$ can be proposed as the following equation.

$$
\text { Mbest }_{d}^{j}=\sum_{j=1}^{N} \frac{p_{d}^{j}}{N}
$$

During the whole procedure, the local optimal value would be updated. The overall process is described in Algorithm 3

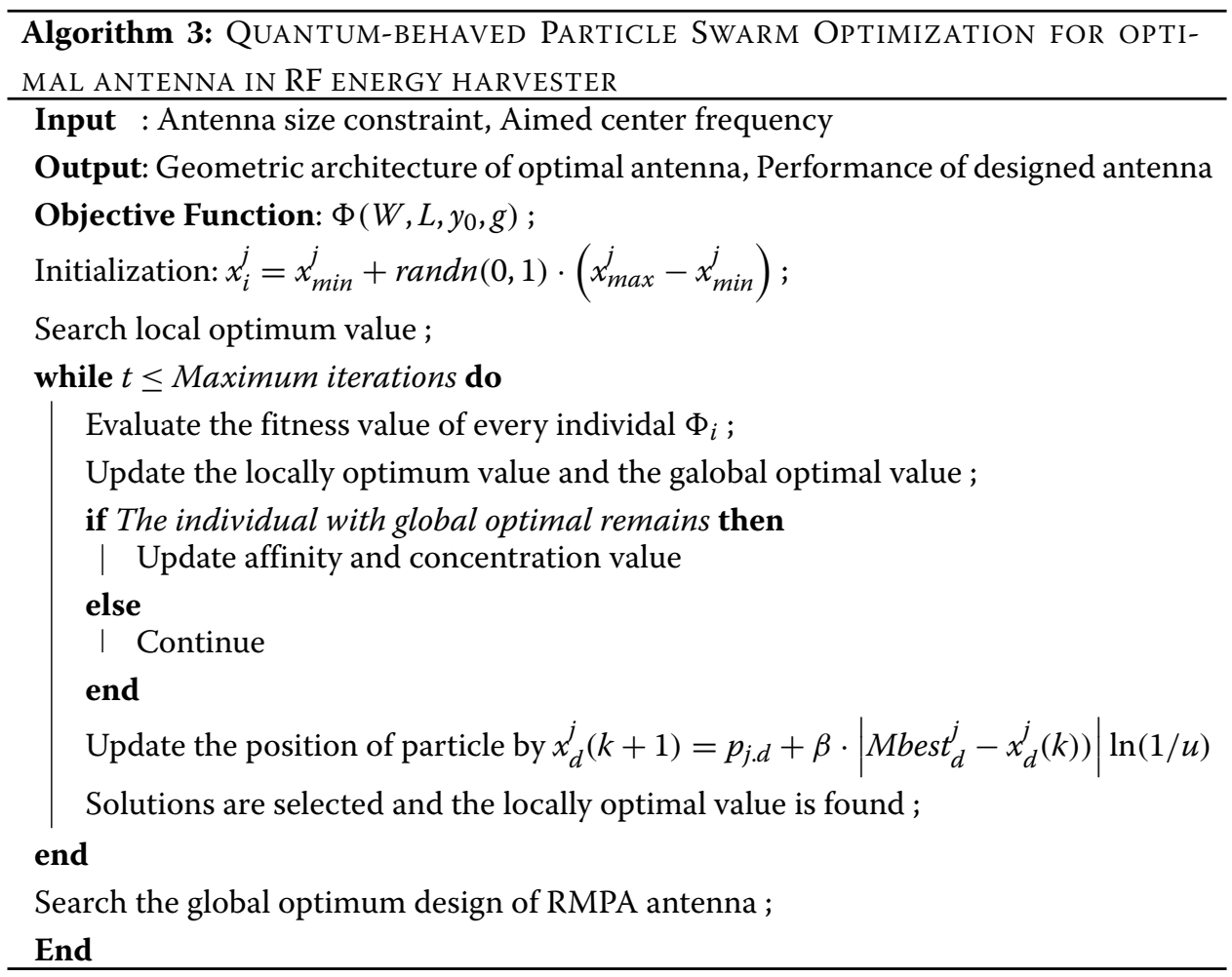


Table 5 Some assumed properties of designed antenna

\begin{tabular}{ll}
\hline Parameter & Value \\
\hline Height of substrate & $1.588 \mathrm{~mm}$ \\
Dielectric constant & 4.4 \\
Loss tangent & 0.008 \\
\hline
\end{tabular}

\section{Results}

The GSM1800 frequency band has been considered to test the validity of the proposed algorithms. The objective function has already been mentioned in Eq. (2), and the weight matrix $\mathbf{W}$ was set to $[0.3,0.4,0.3]$. Some assumed antenna properties have been shown in Table 5 .

\section{Optimal antenna for GSM1800}

The GSM1800 band is allocated in the frequency band $1805.2 \sim 1879.8 \mathrm{MHz}$ (Downlink), and the three separate optimization technologies have been utilized under two different antenna size constraints including in antenna size less of than $100 \mathrm{~mm}$ as well as an antenna size of less than $150 \mathrm{~mm}$. Additionally, the parameters which are used in the QPSO, CS, and DE algorithms are shown in the Table 6. The proposed algorithms were all implemented in MATLAB and Python, and executed on an Intel core ${ }^{T M}$ i5 duo PC with $3.10 \mathrm{GHz}$ CPU and 8 GB RAM.

\section{Test case 1: antenna size should be less than $100 \mathrm{~mm}$}

For the case that antenna size should be less than $100 \mathrm{~mm}$, the comparison of objective function values against a number of iterations for each of the three algorithms is shown in Fig. 6. The proposed algorithms successfully converge on their minimum solutions. Moreover, the graph illustrates that the DE algorithm performs better than the other two approaches in terms of overall convergence performance. The CS algorithm did not give as effective a convergence ability in comparison to the QPSO and DE approaches in the simulation. The results of simulating the proposed optimal antenna designs obtained from the three bio-inspired algorithms are listed in Table 7.

Table 6 Parameters setting of algorithms QPSO, CS, and DE

\begin{tabular}{lll}
\hline Algorithms & Parameter & Value \\
\hline QPSO & $\alpha$ & 0.75 \\
& Max iterations & 500 \\
& Population size & 20 \\
CS & $P a$ & 0.3 \\
& Number of nest & 20 \\
& Max generation & 500 \\
& $\beta$ & 1 \\
DE & Mutation strategy & DE/rand-to-best/1 \\
& Crossover strategy & binomial crossover \\
& $F$ & 0.5 \\
& CR & 0.3 \\
& Numbers of population & 20 \\
Max generation & 500 \\
\hline
\end{tabular}




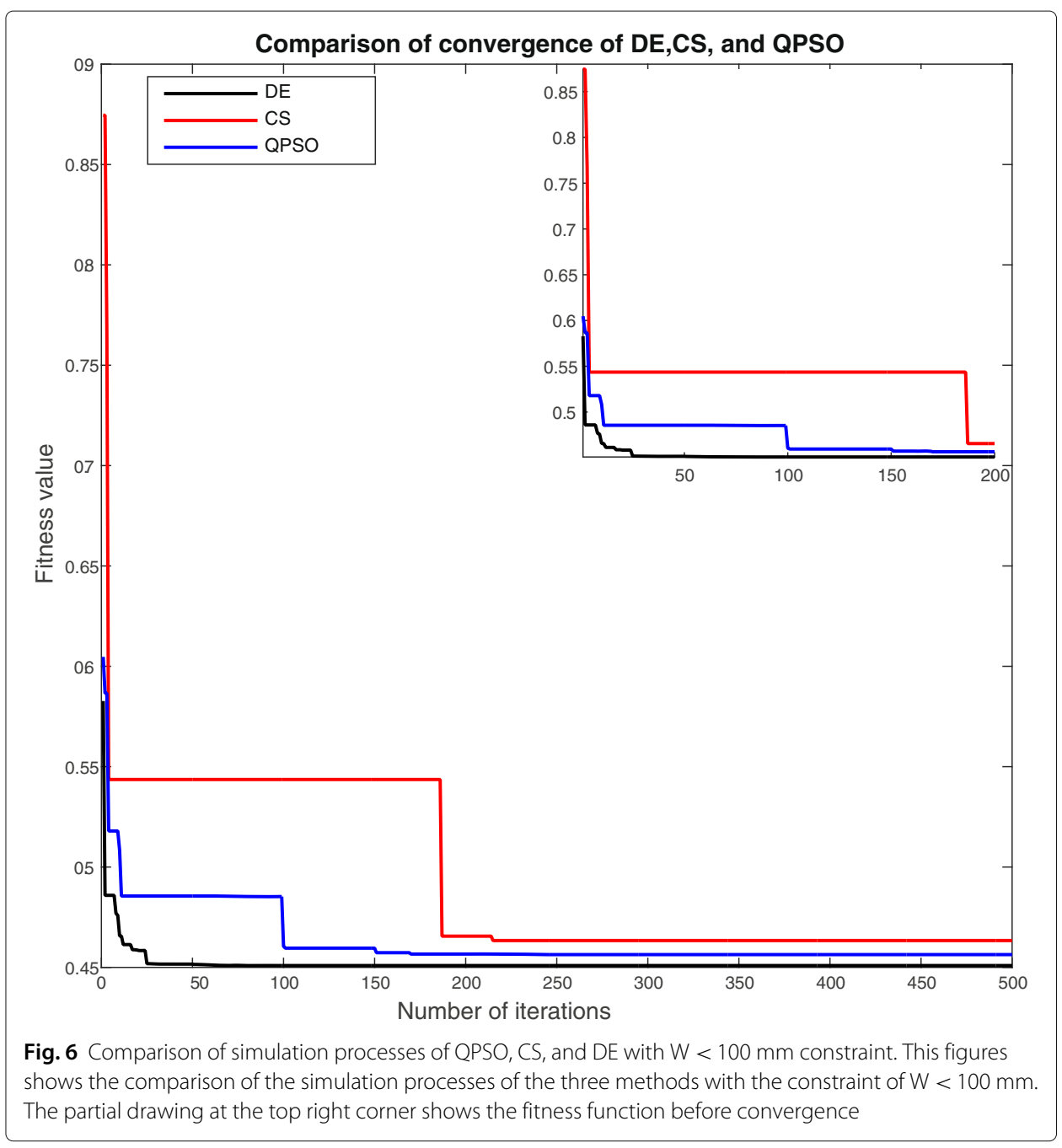

Test case 2: antenna size should be less than $150 \mathrm{~mm}$

Similar results are obtained when the antenna size has to be less than $150 \mathrm{~mm}$. The convergence characteristics of the three optimization methods are shown in Fig. 7, and it indicates that both the DE and QPSO algorithms are effective, each with a high location accuracy and fast convergence speed. The detailed design parameters for the case 2 where antenna size must be less than $150 \mathrm{~mm}$ are shown in Table 8 .

Table 7 Summary of the properties of designed antenna based on QPSO, CS, and DE for antenna size less than $100 \mathrm{~mm}$

\begin{tabular}{llll}
\hline Property & DE & CS & QPSO \\
\hline Antenna gain (dBi) & 3.01 & 2.812 & 2.932 \\
Antenna effciency & 0.445 & 0.425 & 0.435 \\
Efficient bandwidth ratio & 0.3463 & 0.3263 & 0.3383 \\
Patch width $(\mathrm{mm})$ & 99.711 & 90.529 & 96.483 \\
Patch length $(\mathrm{mm})$ & 37.448 & 37.664 & 37.571 \\
Inset feed length $(\mathrm{mm})$ & 9.032 & 27.279 & 27.354 \\
Notch width $(\mathrm{mm})$ & 0.256 & 0.2574 & 0.2568 \\
Run time $(\mathrm{s})$ & 66.2068 & 100.621 & 59.156 \\
\hline
\end{tabular}




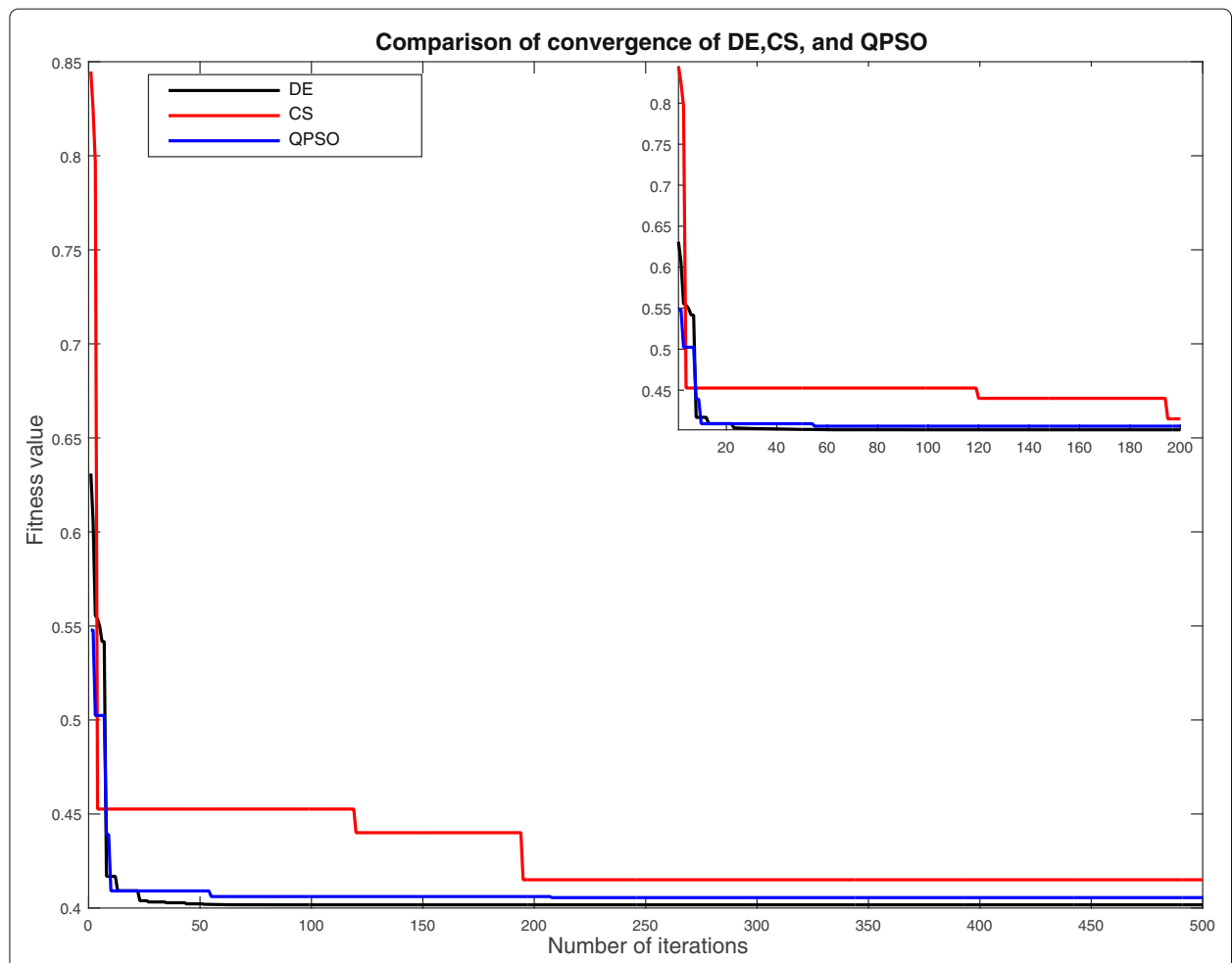

Fig. 7 Comparison of simulation processes of QPSO, CS, and DE with $\mathrm{W}<150 \mathrm{~mm}$ constraint. This figures shows the comparison of the simulation processes of the three methods with the constraint of $W<150 \mathrm{~mm}$. The partial drawing at the top right corner shows the fitness function before convergence

\section{Discussion}

On comparing Figs. 8 and 9, it can be seen that the antennas designed based on each of the three bio-inspired algorithms provide significantly improved properties especially for antenna gain (Fig. 8a) and the bandwidth (Fig. 9a) over non-optimised solutions. Amongst the three optimization approaches, the DE solution offers the widest bandwidth, highest antenna efficiency, and highest antenna gain, identifying that the DE algorithm has an excellent global search ability. In addition, the QPSO based technology presents its incomparable fast and robust convergence ability as shown in Fig. 9b. With the same number of iteration, the speed of convergence of QPSO is 50.44\% faster than the CS, and 39.23\% faster the DE algorithm. Results in Fig. 8b indicates that the CS algorithm has the best robustness performance. On contrast, DE is sensitive to the parameters used in

Table 8 Comparison between the properties of designed antenna based on QPSO, CS, and DE for antenna size less than $150 \mathrm{~mm}$

\begin{tabular}{llll}
\hline Property & DE & CS & QPSO \\
\hline Antenna gain $(\mathrm{dBi})$ & 3.82 & 3.78 & 3.736 \\
Antenna effciency & 0.4902 & 0.45 & 0.483 \\
Efficient bandwidth ratio & 0.425 & 0.4115 & 0.411 \\
Patch width $(\mathrm{mm})$ & 150 & 147.1 & 149.04 \\
Patch length $(\mathrm{mm})$ & 37.294 & 37.285 & 37.75 \\
Inset feed length $(\mathrm{mm})$ & 2.2649 & 29.21 & $3.23 \cdot 10^{-5}$ \\
Notch width $(\mathrm{mm})$ & 0.2549 & 0.2549 & 0.0374 \\
Run time $(\mathrm{s})$ & 92.181 & 99.606 & 66.2068 \\
\hline
\end{tabular}




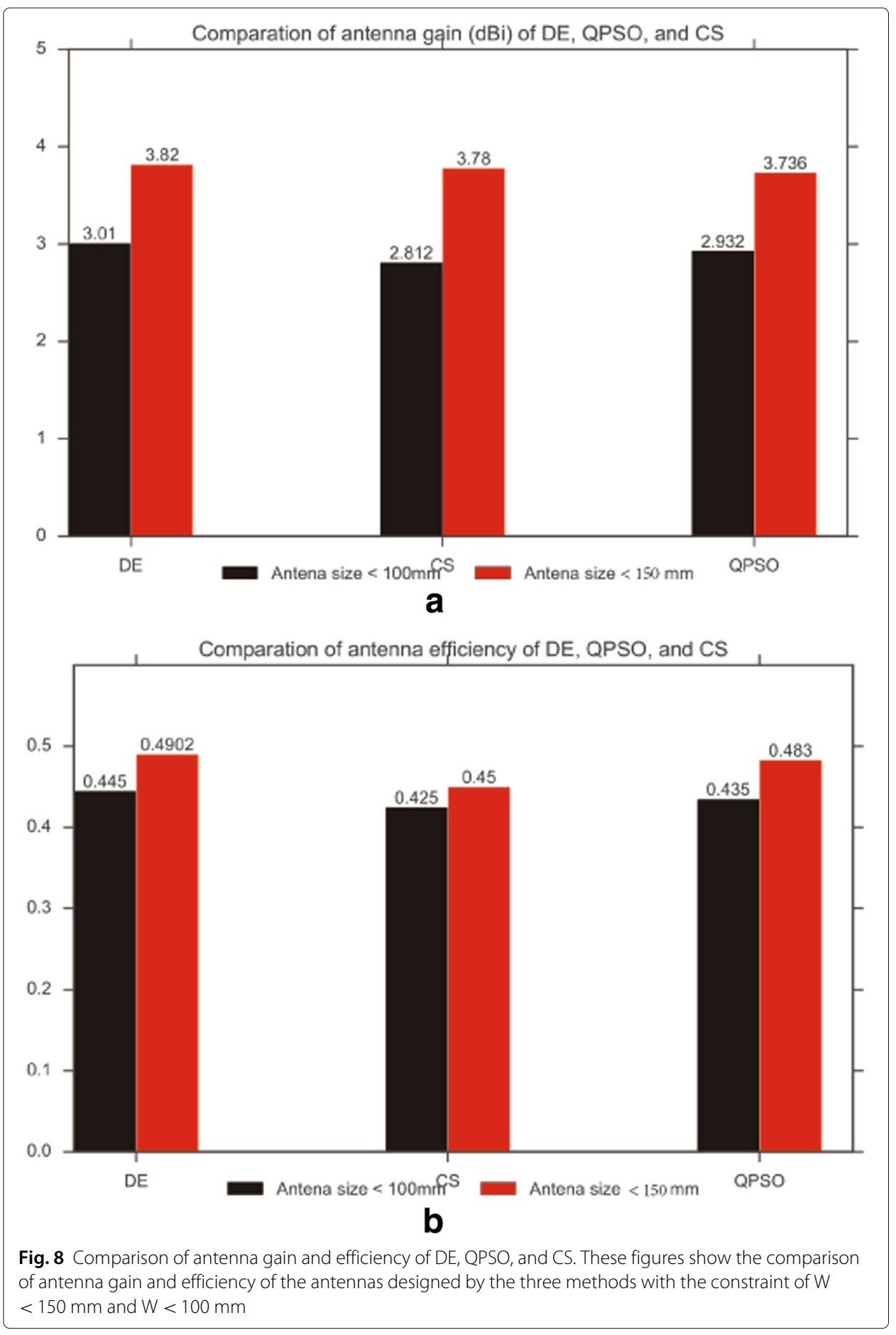

the simulation. Furthermore, the two tests also show that the increase of antenna size can potentially boost the performance of the antenna. In other words, there is a trade-off between the minimization of antenna size and the antenna performance.

\section{Conclusion}

The general anatomy of an RF energy harvester has been explained and examined. Some state of the art designs for receiving antenna including both narrow-band and broad 


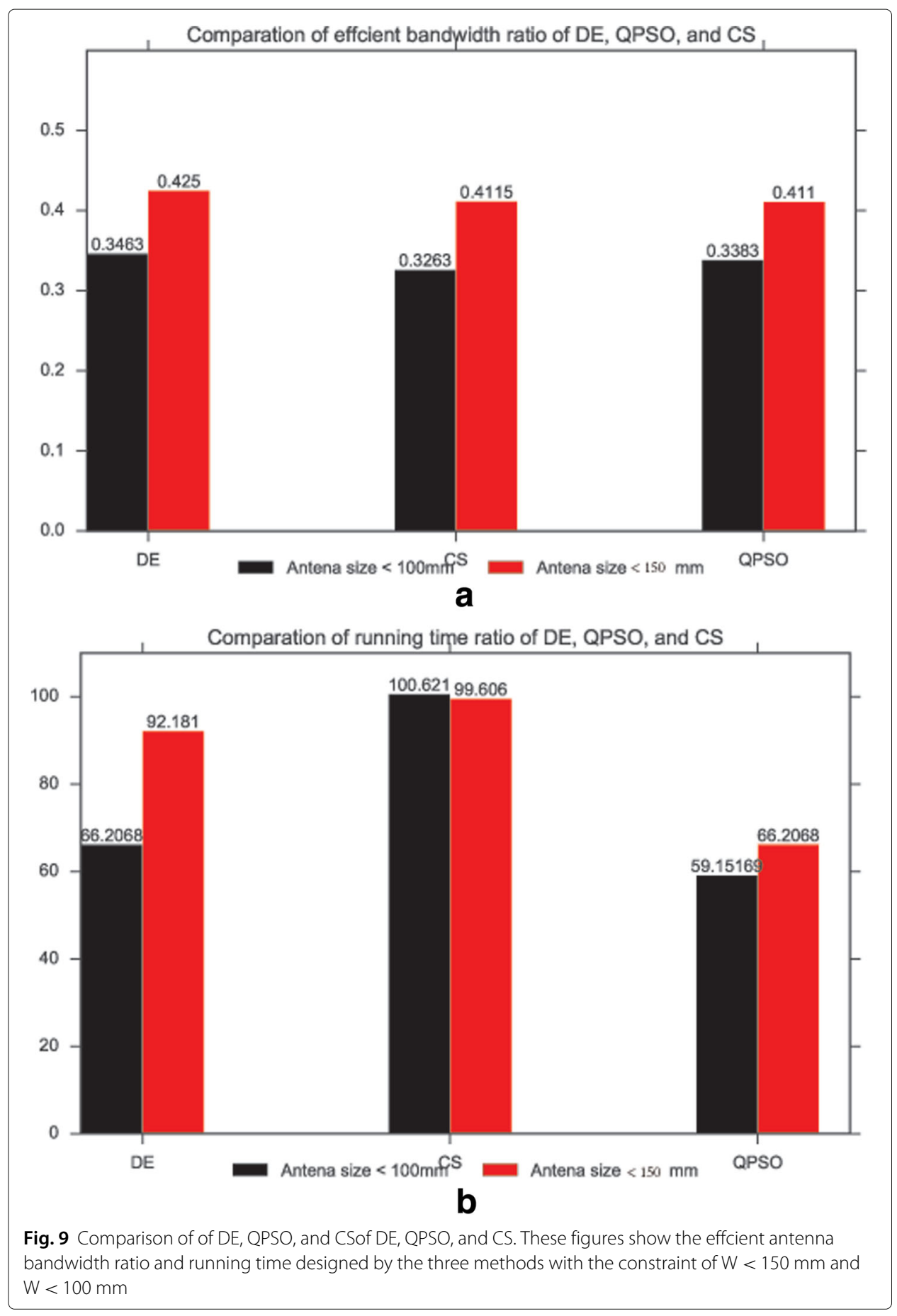

band antennas have been introduced. In the second part, a mathematical weighted evaluation model involving antenna efficiency, center frequency, bandwidth, and gain was proposed to evaluate the performance of a RMPA for a RF harvesting system.The heuristic optimization approaches CS, DE, and QPSO were introduced and then utilized to give optimal designs for a GSM1800 receiving antenna. The proposed optimization algorithms successfully achieved optimal solutions under two different antenna size constraints. The overall comparison between QPSO, DE, and CS showed that the DE based optimization 
design approach provides the best solution and hence has the best globally optimum value search ability. This can significantly enhance antenna performance. Moreover, among the three optimization approaches, the CS algorithm has the best robustness. Furthermore, the simulations using QPSO based algorithm indicate its superiority displaying a faster convergence speed than DE and CS in the application of solving a complex electromagnetic problem.

\section{Acknowledgements}

Not applicable.

Funding

Not applicable.

Availability of data and materials

All data generated or analyzed during this study are included in this paper and reference list.

\section{Author's contributions}

All of the authors read and approved the final manuscript.

Ethics approval and consent to participate

Not applicable.

\section{Consent for publication}

Not applicable.

\section{Competing interests}

The authors declare that they have no competing interests.

\section{Publisher's Note}

Springer Nature remains neutral with regard to jurisdictional claims in published maps and institutional affiliations.

Received: 7 September 2017 Accepted: 30 November 2017

Published online: 03 January 2018

\section{References}

1. McHenry MP, Oakley J, Bräunl T. Limitations of testing standards for battery electric vehicles: accessories, energy usage, and range. IET Electr Syst Transp. 2016;6(3):215-21. doi:10.1049/iet-est.2015.0031.

2. Zhou X, Ho CK, Zhang R, Member S. Wireless Power Meets Energy Harvesting : A Joint Energy Allocation Approach in OFDM-Based System. IEEE Trans Wireless Commun. 2016;15(5):3481-491. doi:10.1109/TWC.2016.2522410. 1410.1266.

3. Soyata T, Copeland L, Heinzelman W. RF Energy Harvesting for Embedded Systems: A Survey of Tradeoffs and Methodology. IEEE Circ Syst Mag. 2016;16(1):22-57. doi:10.1109/MCAS.2015.2510198.

4. Visser HJ, Vullers RJM. RF energy harvesting and transport for wireless sensor network applications: Principles and requirements. Proc IEEE. 2013;101(6):1410-1423. doi:10.1109/JPROC.2013.2250891.

5. Zakaria Z, Zainuddin NA, Husain MN, Abidin MZ, Aziz A, Mutalib MA, Othman AR. Current Developments of RF Energy Harvesting System for Wireless Sensor Networks. Adv Inform Sci Service Sci (AISS). 2013;5(June 2013):328-38. doi:10.4156/AISS.vol5.issue11.39.

6. Lu X, Wang P, Niyato D, Kim DI, Han Z. Wireless networks with rf energy harvesting: A contemporary survey. IEEE Commun Surv Tutorials. 2015;17(2):757-89. doi:10.1109/COMST.2014.2368999. arXiv:1406.6470v4.

7. Ghazanfari A, Tabassum H, Hossain E. Ambient RF energy harvesting in ultra-dense small cell networks: Performance and trade-offs. IEEE Wireless Commun. 2016;23(2):38-45. doi:10.1109/MWC.2016.7462483.

8. Piñuela M, Mitcheson PD, Lucyszyn S. Ambient RF energy harvesting in urban and semi-urban environments. IEEE Trans Microw Theory Tech. 2013;61(7):2715-726. doi:10.1109/TMTT.2013.2262687.

9. Derneryd A. A theoretical investigation of the rectangular microstrip antenna element. IEEE Trans Antennas Propag. 1978;26(4):532-5.

10. Zeng MW, Andrenko AS, Liu X, Tan H-z, Zhu B. Design of Fractal Loop Antenna with Integrated Ground Plane for RF Energy Harvesting. In: 2016 IEEE International Conference on Mathematical Methods in Electromagnetic Theory (MMET). 2016. p. 384-7. http://ieeexplore.ieee.org/document/7543970/.

11. Arrawatia M, Baghini MS, Kumar G. Broadband Bent Triangular Omnidirectional Antenna for RF Energy Harvesting. IEEE Antennas Wireless Propag Letters. 2016;15:36-9. doi:10.1109/LAWP.2015.2427232.

12. Ivanov IK, Rehman MU, Allen B. Printed Microstrip Antenna for Harvesting Energy from Mobile Phone Base Stations. In: Antennas and Propagation (EuCAP), 2016 10th European Conference On. p. 2-6. http://ieeexplore.iee.org/ document/7481813/.

13. Wen J, Xie D, Liu X, Guo H, Liu C, Yang X. Wideband collar-shaped antenna for RF energy harvesting. In: 2016 Asia-Pacific International Symposium on Electromagnetic Compatibility (APEMC). 2016. p. 253-5. doi:10.1109/APEMC.2016.7523025.

14. Yang D, Qu J, Zhao Z, Liu S, Nie Z. Planar quasi-Yagi antenna with band rejection based on dual dipole structure for UWB. IET Microwaves Antennas Propag. 2016;10(15):1708-1714. doi:10.1049/iet-map.2016.0160. 
15. Maher R, Tammam E, Ahmed I. Galal, Hamed HF. Design of A Broadband Planar Antenna for RF Energy Harvesting. In: International Conference on Electrical, Electronics, and Optimization Techniques (ICEEOT). 2016. p. 1808-10. http://ieeexplore.ieee.org/document/7754999/.

16. Li JY, Xu R, Zhou SG, Zhang X, Yang GW. A Wideband High-Gain Cavity-Backed Low-Profile Dipole Antenna. IEEE Trans Antennas Propag. 2016;64(12):1-1. doi:10.1109/TAP.2016.2620607.

17. Simorangkir RBVB, Abbas SM, Esselle KP. A Printed UWB Antenna with Full Ground Plane for WBAN Applications. In: Antenna Technology (iWAT), 2016 International Workshop On. 2016. p. 127-30. http://ieeexplore.ieee.org/ document/7434821\%.

18. Mohammed HJ, Abdullah AS, Ali RS, Abd-alhameed RA, Abdulraheem YI, Noras JM. Design of a uniplanar printed triple band- rejected ultra-wideband antenna using particle swarm optimisation and the firefly algorithm. IET Microwaves Antennas Propag. 2016;10:31-7. doi:10.1049/iet-map.2014.0736.

19. Gregory MD, Martin SV, Werner DH. Improved Electromagnetics Optimization. IEEE Antennas Propag Mag. 2015;june. http://ieeexplore.ieee.org/document/7163535/.

20. Gangopadhyaya M, Mukherjee P, Gupta B. Resonant Frequency Optimization of Coaxially Fed Rectangular Microstrip Antenna Using Cuckoo Search Algorithm. 2016 IEEE 7th Annual Information Technology, Electronics and Mobile Communication Conference (IEMCON) 2016. 2016;2:1-4.

21. Manna S, Sharma U, Gangopadhyaya M, Mukherjee P, Gupta B, Ghose R. Comparative Study of Cuckoo Search Optimization and Differential Evolution Algorithm for Design of Microstrip fed Microstrip Patch Antenna. In: 2015 International Conference and Workshop on Computing and Communication (IEMCON). 2015. http://ieeexplore.ieee. org/document/7344439/.

22. Kumar M, Sahoo AB, Sao R, Mangaraj BB. Optimization of rectangular patch antenna at $5 \mathrm{GHz}$ using bat search algorithm. Proceedings - 2015 5th International Conference on Communication Systems and Network Technologies, CSNT 2015. 2015;4:68-72. doi:10.1109/CSNT.2015.47.

23. Mishra S, Chattopadya IS, Gangopadhyaya M. A comparative study of DE, PSO and BFO for optimisation of Rectangular Microstrip Patch Antenna with inset feed parameter. In: 2015 International Conference and Workshop on Computing and Communication (IEMCON). 2015. http://ieeexplore.ieee.org/document/7344470/.

24. Carver K, Mink J. Microstrip antenna technology. IEEE Trans Antennas Propag. 1981;29(1):2-24.

25. Dey S, Mittra R. Compact microstrip patch antenna. Microw Opt Technol Lett. 1996;13(1):12-14.

26. Guha D, Biswas M, Antar YM. Microstrip patch antenna with defected ground structure for cross polarization suppression. IEEE Antennas Wireless Propag Letters. 2005;4(1):455-8.

27. Matin MA, Sayeed Al. A design rule for inset-fed rectangular microstrip patch antenna. WSEAS Trans Commun. 2010;9(1):63-72

28. P PV. B Uckling of R Ectangular P Lates Under. International J Eng Sci Emerging Technol. 2012;3(2):1-12.

29. Yang XS, Deb S. Cuckoo Search via Lévy Flights. In: 2009 World Congress on Nature \& Biologically Inspired Computing (NaBIC 2009). http://ieeexplore.ieee.org/document/5393690/.

30. Arora S, Singh S. A conceptual comparison of firefly algorithm, bat algorithm and cuckoo search. In: 2013 International Conference on Control, Computing, Communication and Materials, ICCCCM. 2013. doi:10.1109/ICCCCM.2013.6648902.

31. Qin AK, Huang VL, Suganthan PN. Differential evolution algorithm with strategy adaptation for global numerical optimization. IEEE Transactions on Evolutionary Computation. 2009. doi:10.1109/TEVC.2008.927706.

32. Das S, Suganthan PN. Differential evolution: A survey of the state-of-the-art. IEEE Transactions on Evolutionary Computation. 2011. doi:10.1109/TEVC.2010.2059031.

33. Brest J, Greiner S, Boškovi B, Mernik M, Zumer V. Self-Adapting Control Parameters in Differential Evolution: A Comparative Study on Numerical Benchmark Problems. IEEE Trans Evol Comput. 2006;10(6). doi:10.1109/TEVC.2006.872133.

34. Mikki SM, Member S, Kishk AA. Quantum Particle Swarm Optimization for Electromagnetics. 2006;54(10): 2764-2775. http://ieeexplore.ieee.org/document/1707913/.

35. Ho SL, Yang S, Ni G, Huang J. A Quantum-Based Particle Swarm Optimization Algorithm Applied to Inverse Problems. 2013;49(5):2069-2072. http://ieeexplore.ieee.org/document/6514656/.

36. Soman S, Jayadeva, Suri M. Recent trends in neuromorphic engineering. Big Data Analytics. 2016;1 (1):15. doi:10.1186/s41044-016-0013-1.

37. Cheng S, Liu B, Ting TO, Qin Q, Shi Y, Huang K. Survey on data science with population-based algorithms. Big Data Analytics. 2016;1 (1):3. doi:10.1186/s41044-016-0003-3.

38. Meng K, Wang HG, Dong Z, Member S, Wong KP. Quantum-Inspired Particle Swarm Optimization for Valve-Point Economic Load Dispatch. 2010;25(1):215-222. http://ieeexplore.ieee.org/document/5299292/.

39. Arrawatia M, Baghini M, Kumar G. Differential Microstrip Antenna for RF Energy Harvesting. IEEE Trans Antennas Propag. 2015;PP(99):1-1. doi:10.1109/TAP.2015.2399939.

40. Ghosh S. Design and Testing of RF Energy Harvesting Module in GSM 900 Band using Circularly Polarized Antenna. In: 2015 IEEE International Conference on Research in Computational Intelligence and Communication Networks (ICRCICN). 2015. p. 386-9. http://ieeexplore.ieee.org/document/7434269/.

41. Saghlatoon H, Bjorninen T, Sydanheimo L, Tentzeris MM, Ukkonen L. Inkjet-printed wideband planar monopole antenna on cardboard for RF energy-harvesting applications. IEEE Antennas Wirel Propag Lett. 2015;14:325-8. doi:10.1109/LAWP.2014.2363085.

42. Dadgarpour A, Zarghooni B, Virdee BS, Denidni TA. High-gain end-fire bow-tie antenna using artificial dielectric layers. IET Microw Antennas Propag. 2015;9(12):1254-1259. doi:10.1049/iet-map.2014.0514.

43. Han W, Yang F, Ouyang J, Yang P. Epsilon-Negative Transmission-Line-Based Annular-Ring-Loaded Circular Microstrip Antenna. 2016;15:1799-1802. http://ieeexplore.ieee.org/document/7423694/. 